\title{
Choroidal neovascularization due to punctate inner choroidopathy: long-term follow-up and review of literature
}

This article was published in the following Dove Press journal:

Clinical Ophthalmology

27 July 2010

Number of times this article has been viewed

\section{Dimitrios Brouzas \\ Antonios Charakidas \\ Tryfon Rotsos \\ Marilita M Moschos \\ Helen Loukianou \\ Chryssanthy Koutsandrea \\ loannis Ladas \\ Stefanos Baltatzis}

First Department of Ophthalmology, University of Athens Medical School, Athens, Greece
Correspondence: Dimitrios Brouzas I0 G. Papandreou St, Byron-Athens 16231 , Greece

Tel +302I0 7652909

Fax +302107652909

Emailbrouzas@yahoo.com
Introduction: The aim of the article was to report on the long-term follow-up of choroidal neovascularization (CNV) cases secondary to punctate inner choroidopathy (PIC) either treated with photodynamic therapy (PDT) or followed without treatment. A comprehensive review of existing literature on the various treatment modalities is incorporated.

Methods: Nine eyes of 8 female patients with CNV due to PIC were followed retrospectively for an average of 105 months (range, 36-162 months). Mean age of the patient cohort on presentation was 28 years (range, 21-39). Four eyes were treated with PDT, whereas in 4 patients, including 1 with bilateral involvement, the disease followed its natural course without treatment. Snellen visual acuity and the extent of neovascularization and subretinal fibrosis were evaluated on presentation and at the end of the follow-up period.

Results: Improvement of vision was observed in 6 eyes $(66.7 \%)$, including all cases treated with PDT, and in 2 of 5 eyes left untreated. The size of the neovascular lesion, including both CNV and subretinal fibrosis, increased in all cases left untreated $(55.6 \%)$ and remained stable in all cases treated with PDT (44.4\%).

Conclusion: Without treatment, the CNV due to PIC is slowly progressive. Our short cohort appears to have benefited from PDT in terms of maintaining visual acuity and stabilizing the extent of CNV and fibrosis.

Keywords: PIC natural course, PIC treatment

\section{Introduction}

Punctate inner choroidopathy (PIC) is an inflammatory chorioretinal disease of unknown etiology, first described by Watzke et al in $1984 .{ }^{1}$ It presents mostly in healthy, young, moderately myopic women ${ }^{2}$ with metamorphopsia and decreased visual acuity. On fundoscopy, small, creamy, yellow-white lesions, measuring 100-300 $\mu \mathrm{m}$, located in the retinal pigment epithelium and inner choroid without concomitant intraocular inflammation are the hallmark of the early disease. ${ }^{2}$ The optic nerve head can be mildly swollen. ${ }^{3}$ Fluorescein angiography (FA) reveals areas with early hyperfluorescence and late leakage, ${ }^{3}$ whereas, remarkably, on indocyanine green angiography, more hypofluorescent spots than observed clinically or on FA are evident, with normal large choroidal vessels running through the hypofluorescent areas. ${ }^{3,4}$ At least $25 \%-40 \%$ of patients develop choroidal neovascularization (CNV), usually within the first 6 months, although CNV may occur years after the initial lesions. For the remaining $60 \%-75 \%$, the visual prognosis is rather favorable with the majority of eyes retaining vision of $20 / 30$ or better. ${ }^{2,4,5}$ 
The variety of treatment options for the CNV in PIC reflects the puzzling absence of consistent results and includes submacular surgery, ${ }^{6,7}$ steroids, ${ }^{4,8,9}$ photodynamic therapy (PDT), ${ }^{10-16}$ and most recently anti-VEGF agents. ${ }^{17,18}$ In cases of extrafoveal or juxtafoveal lesion, CNV laser photocoagulation can also be attempted. ${ }^{4}$ We report on the long-term outcome of a cohort of young adults with PIC complicated with CNV who either underwent PDT or left to follow the natural course of the disease.

\section{Patients and methods}

The charts of patients with a definite diagnosis of PIC from September 1993 were identified and reviewed. A total of 9 eyes of 8 patients with actively leaking CNV were included in the study and retrospectively followed for a total of 36-162 months (average, 105 months). In 1 patient, there was bilateral involvement, whereas in 7 patients, the $\mathrm{CNV}$ was unilateral. Four eyes were treated with PDT, and 5 eyes were left untreated. The latter was considered an established treatment modality for $\mathrm{CNV}$, before the introduction of PDT. The patient who suffered bilateral involvement was also administered interferon-2b (IFN-2b; 3 MU subcutaneously 3 times per week) for viral hepatitis-B diagnosed during the initial workup, and 1 patient had been treated with thermal laser prior to PDT (Table 1).

Treatment with PDT followed the standard protocol and consisted of an intravenous infusion of $6 \mathrm{mg} / \mathrm{m}^{2}$ verteporfin (Visudyne ${ }^{\circledR}$; Novartis AG, Bülach, Switzerland) for 10 minutes. Fifteen minutes after the initiation of the infusion, the photosensitizer was activated using a laser light of $689 \mathrm{~nm}$ delivered at $50 \mathrm{~J} / \mathrm{cm}^{2}$ with an intensity of $600 \mathrm{~mW} / \mathrm{cm}^{2}$ for 83 seconds. The treatment spot was set to cover the greatest linear dimension of the CNV lesion, with an additional $500 \mu \mathrm{m}$ covering the borders on each side. FA was performed prior to PDT to evaluate the extent of $\mathrm{CNV}$ and repeated during follow-up to evaluate the CNV activity. Retreatment was considered in cases of residual leakage or reactivation.

Studied parameters included Snellen visual acuity and the extent of active neovascularization and subretinal fibrosis, as evaluated by reviewing the FA on presentation and at the end of follow-up period. Patient demographics, treatment, and final results are summarized in Table 1.

\section{Results}

\section{Report of selected cases}

\section{Patient I}

A 36-year-old female myopic patient was initially referred in June 2001 with a right-sided visual impairment of 6-weeks duration. On presentation, best-corrected visual acuity (BCVA) amounted to 20/400 OD (ocular dexter) and 20/20 OS (ocular sinister) with a corresponding refractive error of $-4.0 \mathrm{D}$ and $-2.5 \mathrm{D}$. Fundus examination revealed several scattered chorioretinal scars on the posterior pole of the affected eye and an extensive submacular exudative lesion, which angiographically corresponded to $\mathrm{CNV}$ (Figure 1A). PIC complicated with subfoveal CNV was diagnosed. The patient underwent standard PDT with a 4,200- $\mu \mathrm{m}$ spot size on July 2001, repeated once on February 2002. Three months following the second PDT session, BCVA had improved to 20/100 OD. Visual acuity remained stable during the follow-up period, whereas on FA a central chorioretinal scar without signs of leakage was evident (Figure 1B).

Table I Patient demographics, refraction, and clinical course

\begin{tabular}{|c|c|c|c|c|c|c|c|c|c|}
\hline Patient no. & $\begin{array}{l}\text { Age at } \\
\text { presentation }\end{array}$ & Gender & Eye & Refraction & Initial VA ${ }^{a}$ & $\begin{array}{l}\text { Treatment } \\
\text { (sessions) }\end{array}$ & $\begin{array}{l}\text { Follow-up } \\
\text { (months) }\end{array}$ & Final VA $^{a}$ & $\begin{array}{l}\text { CNV-subretinal } \\
\text { fibrosis extent }\end{array}$ \\
\hline I & 36 & $\mathrm{~F}$ & OD & -4.0 & $20 / 400$ & PDT (2) & 72 & $20 / 100$ & Stable \\
\hline 2 & 21 & $\mathrm{~F}$ & OS & -3.75 to $0.75 \times 20$ & $20 / 400$ & PDT (2) & 36 & $20 / 25$ & Stable \\
\hline 3 & 35 & $\mathrm{~F}$ & OS & -3.0 to $0.5 \times 180$ & $20 / 400$ & None & 124 & $20 / 800$ & Increased \\
\hline 4 & 29 & $\mathrm{~F}$ & OS & -2.5 & $20 / 80$ & None & 126 & $20 / 40$ & Increased \\
\hline 5 & 22 & $\mathrm{~F}$ & OD & -2.0 & $20 / 25$ & None & 159 & $20 / 50$ & Increased \\
\hline- & - & - & OS & -3.0 & $20 / 40$ & None & 162 & $20 / 100$ & Increased \\
\hline 6 & 24 & $\mathrm{~F}$ & OD & -3.0 to $0.75 \times 115$ & $20 / 70$ & None & 134 & $20 / 30$ & Increased \\
\hline 7 & 39 & $\mathrm{~F}$ & OS & -1.75 to $0.75 \times 90$ & $20 / 50$ & PDT (I) & 48 & $20 / 30$ & Stable \\
\hline 8 & 21 & $\mathrm{~F}$ & OD & -3.0 to $0.75 \times 60$ & $20 / 70$ & $\begin{array}{l}\text { Thermal laser } \\
\text { or PDT (2) }\end{array}$ & 84 & $20 / 25$ & Stable \\
\hline Average & 28 & - & - & - & - & - & 105.0 & - & - \\
\hline
\end{tabular}

Notes: aSnellen. ${ }^{\text {b}}$ Compared with lesion extent on presentation.

Abbreviations: VA, visual acuity; CNV, choroidal neovascularization; OD, oculus dexter; OS, oculus sinister; PDT, photodynamic therapy. 

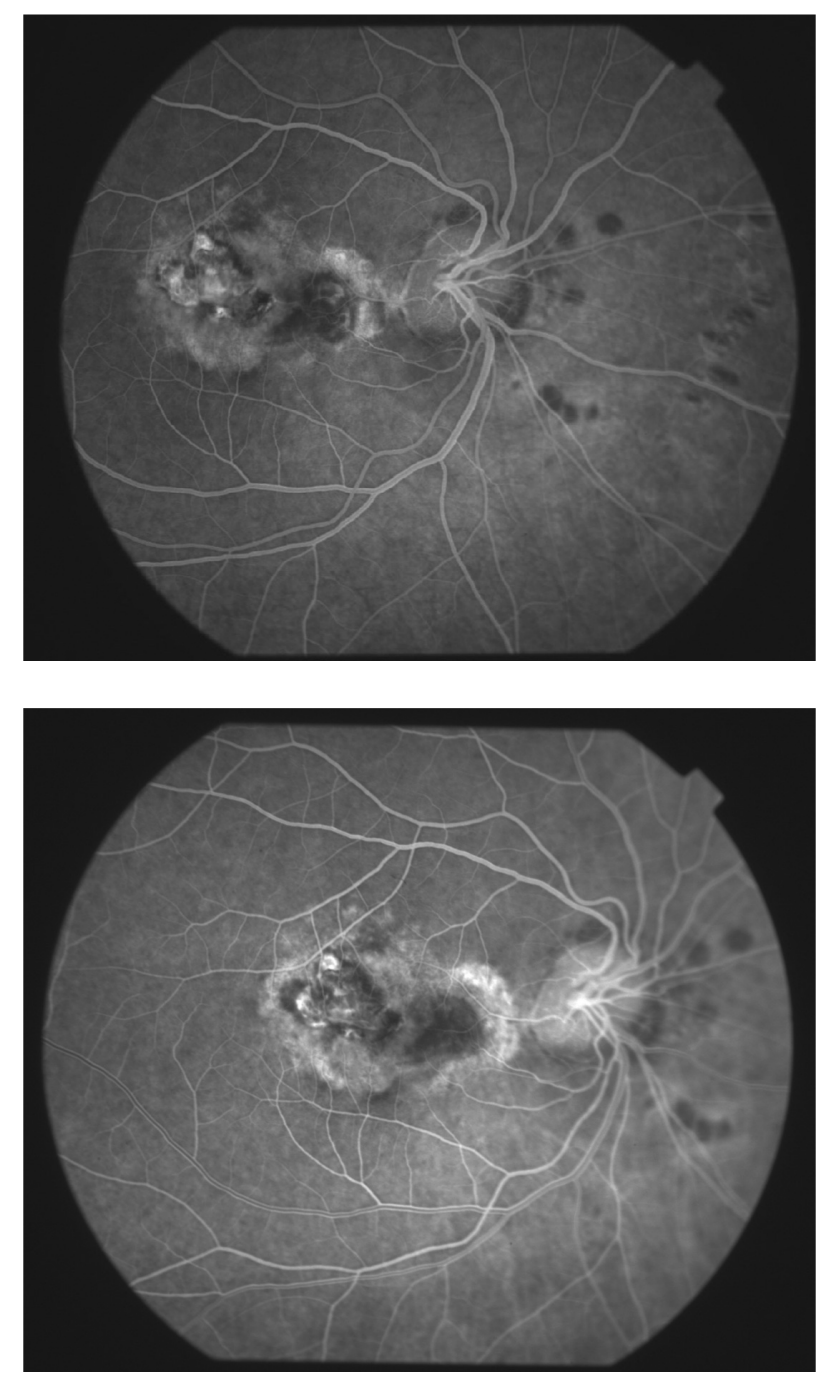

Figure I Case I. Choroidal neovascularization with photodynamic therapy treatment. A) On presentation. B) At the end of 72-month follow-up period. The choroidal neovascularization is stable.

\section{Patient 2}

A 21-year-old female myopic patient was initially referred in June 2004 with a 2-month history of floaters and decrease of vision from the left eye. Her refractive error was OD $-4.5 \mathrm{D}$ and $\mathrm{OS}-3.75$ to $0.75 \times 20$, and on presentation, BCVA was 20/20 and 20/400, respectively. A typical picture of left-sided PIC complicated with CNV was evident on fundoscopy and FA. Upon diagnosis, the patient was treated with PDT with a 4,100- $\mu \mathrm{m}$ spot size. One month later, visual acuity had improved to 20/100 OS, but due to persistence of fluorescein leakage, the patient was retreated with PDT. In December 2004 , visual acuity had improved to 20/30 OS, whereas the CNV remained angiographically inactive. At the end of a 3-year follow-up period, the visual acuity amounted to 20/25 OS without leakage on FA.

\section{Patient 3}

A 35-year-old female myopic patient was referred in October 1996 with decreased vision and metamorphopsia in her left eye of 3 weeks duration. Myopic error was OD $-4.0 \mathrm{D}$ and OS -3.0 to $0.5 \times 180$ with a BCVA of $20 / 40$ and 20/400, respectively. She reported an episode of central serous chorioretinopathy in her right eye 9 years earlier. Based on fundoscopy and FA findings, PIC complicated with subfoveal CNV was diagnosed. None of the treatment options was deemed effective at that time, and the disease was left to follow its natural course. Three months later, her visual acuity improved to $20 / 80$ OS but subsequently deteriorated to less than 20/400 in July 1997. On FA, a large neovascular membrane was evident, which eventually progressed to an extensive disciform chorioretinal scar.

\section{Patient 5}

A 22-year-old female myopic patient was initially referred in September 1993 with left eye visual impairment and metamorphopsia. Refractive error was OD $-2.0 \mathrm{D}$ and OS $-2.5 \mathrm{D}$ with a corresponding BCVA of 20/25 OD and 20/40 OS on Snellen optotype. A left eye subfoveal CNV was evident on FA. On general workup, active hepatitis B was diagnosed, and $\alpha$-IFN-2b (3MU subcutaneously 3 times per week) was administered immediately until February 1994. Three months after her referral, although she was on the IFN treatment, she developed $\mathrm{CNV}$ in the right eye along with several discrete chorioretinal small scars with diameter of approximately 200-300 $\mu \mathrm{m}$ mainly around the optic disc. On February 1996, her visual acuity was 20/50 in the right eye and 20/100 in the left eye, which was stable in all consecutive follow-up examinations. Subsequent FAs confirmed the presence of chrorioretinal scars without leakage bilaterally.

\section{Patient 6}

A 24-year-old female myopic patient ([OD -3.0 to $0.75 \times 115]$ and [OS -4.0 D]) was initially referred in December 1995 with right eye visual impairment and metamorphopsia. BCVA on presentation was 20/70 OD and 20/25 OS. Fundus examination revealed a small exudative lesion that was leaking on FA in the right eye (Figure 2A) and several creamy, yellow-white lesions in the left eye with faint staining in the late phases of FA. None of the current treatment options was deemed effective, and the disease was left to follow its natural course. Three years later, an increase of the size of CNV was noted on FA, although visual acuity had improved to 20/30 OD. In subsequent follow-ups, visual acuity remained stable. 

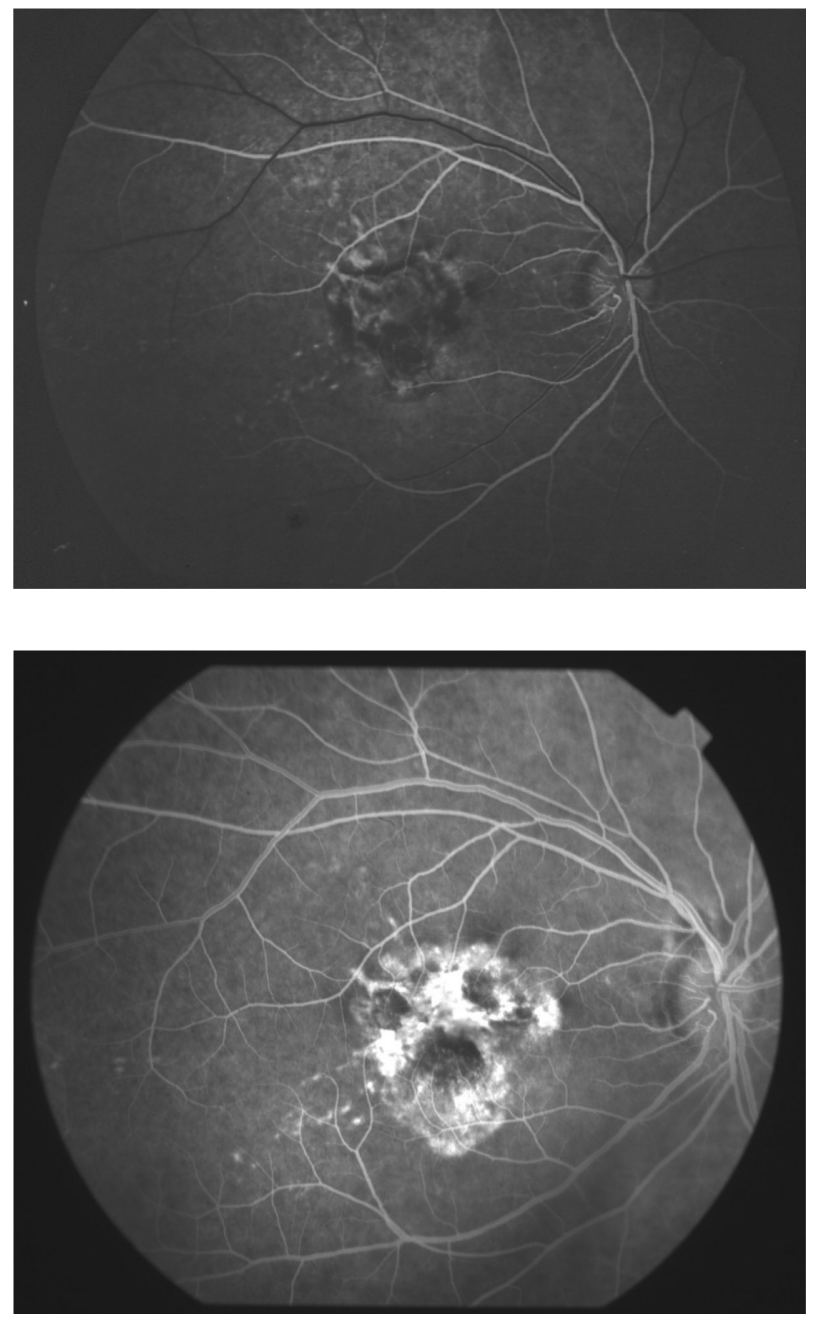

Figure 2 Case 6. Choroidal neovascularization without photodynamic therapy treatment. A) On presentation. B) At the end of 134-month follow-up period. There is an apparent increase of choroidal neovascularization.

On her last visit 11 years after the diagnosis of PIC, visual acuity was 20/30 in the right eye and 20/25 in the left eye, the FA showed juxtafoveal lesions with staining but without leakage in the right eye (Figure 2A) and some scattered chorioretinal slightly pigmented small lesion in the left eye.

Nine eyes of 8 female patients were retrospectively followed for an average of 105 months (range, 36-162 months) after the diagnosis of PIC associated with active CNV. Mean age of the patient group was 28 years (range, 21-39). Four eyes were initially treated with PDT, in 3 of which the treatment was repeated once due to active leakage on subsequent FA. The remaining 5 eyes were followed without treatment mainly due to the lack of a widely accepted effective treatment at the time of presentation.

Visual acuity on presentation measured 20/40 or better in 2 eyes (22.2\%), ranged from 20/40 to 20/200 in 4 eyes (44.4\%), and was $20 / 200$ or worse in 3 eyes $(33.3 \%)$.
Improvement of vision was noted in 6 eyes at the end of the follow-up period (66.7\%), including all cases treated with PDT, and in 2 of 5 eyes left untreated, and visual acuity deterioration was noted in 3 eyes (33.3\%).

The size of the neovascular lesion, including both $\mathrm{CNV}$ and subretinal fibrosis, increased in 5 eyes $(55.6 \%)$ and was stable in 4 eyes (44.4\%) all treated with PDT. A trend toward better final visual acuity and stability of CNV activity was identified in the subgroup receiving PDT.

\section{Discussion}

The management of CNV due to PIC has not been conclusively determined, as most published cohorts (Table 2) report on small number of patients with short follow-up, including some with intermixed subfoveal and juxtafoveal CNV lesions. A variety of treatment options have been described, including PDT, ${ }^{10-16}$ use of local and systemic steroid monotherapy, ${ }^{2,4,9}$ submacular surgery, ${ }^{6,7}$ and recently antiVEGF agents. ${ }^{17,18}$ Corticosteroids have also been advocated as a therapeutic adjunct to PDT, in particular due to their dual anti-inflammatory and antiangiogenetic properties. ${ }^{19,20}$

Oral steroids and laser photocoagulation were tried as early as 1984 by Watzke et al ${ }^{1}$ in their initial presentation of 10 cases of a clinical entity that they termed "PIC". Brown et $\mathrm{al}^{2}$ presented 5 patients who underwent oral and subtenon corticosteroid treatments, which reportedly slowed or stopped the subfoveal neovascularization, though without effect on final visual acuity which was less than 20/200 in all eyes. Submacular surgery was considered as a potential treatment of CNV due to PIC in 1995 by Adelberg et al, ${ }^{7}$ who reported 1 case with more than 2 lines of Snellen acuity gain at the end of the follow-up period. Olsen et $\mathrm{al}^{6}$ in 1996 reported further promising results in 5 patients ( 6 eyes) who underwent submacular surgery and noted visual improvement in all 6 eyes, although recurrences were common (4 out of 6 eyes). Sickenberg et al ${ }^{11}$ in 2000 presented 1 case treated with PDT and followed for 35 weeks with no change in visual acuity (20/100), whereas Rogers et $\mathrm{al}^{10}$ reported on 6 cases of PIC complicated with CNV and treated with PDT, and noted visual improvement in 4 eyes, decline in 1 and, stabilization in 1. Further reports on small cohorts of patients with PIC by Wachtlin et al, ${ }^{12}$ Chatterjee and Gibson, ${ }^{13}$ Postelmans et al, ${ }^{14}$ Lim et al, ${ }^{15}$ and Coco et al ${ }^{16}$ substantiate a general trend toward favorable results with PDT. Fong et $\mathrm{al}^{21}$ and Chan et $\mathrm{al}^{22}$ reported encouraging results on combined PDT with oral or intravitreal steroid. Finally, Vossmerbaeumer et al ${ }^{17}$ reported the successful outcome in a case of CNV secondary to PIC with intravitreal anti-VEGF treatment (bevacizumab), 
Table 2 Summary of existing literature

\begin{tabular}{|c|c|c|c|c|c|}
\hline $\begin{array}{l}\text { Year of } \\
\text { publication }\end{array}$ & Author & No. eyes & Follow-up & Treatment & Comment \\
\hline 1984 & Watzke et al' & 3 & $1,5-8 y$ & No treatment or oral steroids & $\begin{array}{l}\text { Decline in VA to } 20 / 60 \text { in } \\
\text { I eye and } 20 / 200 \text { in } 2 \text { eyes }\end{array}$ \\
\hline 1995 & Adelberg et $\mathrm{al}^{7}$ & I & $13.5 \mathrm{mo}$ & Submacular surgery & From $20 / 300$ to $20 / 70$ \\
\hline 1996 & Brown et $\mathrm{al}^{2}$ & 5 & $6 \mathrm{mo}$ & No treatment or oral steroids & Final $V A \leq 20 / 200$ in all eyes \\
\hline 1996 & Olsen et $\mathrm{al}^{6}$ & 6 & $14 \mathrm{mo}$ & Submacular surgery & $\begin{array}{l}\text { VA improved in all eyes, } \\
66 \% \text { recurrence }\end{array}$ \\
\hline 2000 & Sickenberg et al" & $\mathrm{I}$ & 35 wk & PDT & No change in VA $(20 / 100)$ \\
\hline 2003 & Rogers et al ${ }^{10}$ & $6^{a}$ & $4-33 \mathrm{mo}$ & $\begin{array}{l}\text { PDT or retreatment } \\
\text { in } 4 \text { cases }\end{array}$ & $\begin{array}{l}\text { VA improvement in } 4 \text {, } \\
\text { deterioration in I, and } \\
\text { I with no change }\end{array}$ \\
\hline 2003 & Wachtlin et $\mathrm{al}^{12}$ & $7^{b}$ & $22.1 \mathrm{mo}$ & PDT & $\begin{array}{l}\text { VA improvement in } 63.2 \% \\
\text { of cases }\end{array}$ \\
\hline 2003 & Chatterjee and Gibson ${ }^{13}$ & I & $15 \mathrm{mo}$ & PDT & VA improvement \\
\hline 2005 & Levy et $\mathrm{al}^{4}$ & I & $3 \mathrm{mo}$ & Oral steroids & $\begin{array}{l}\text { VA improvement from } 6 / 60 \\
\text { to } 6 / 9^{d}\end{array}$ \\
\hline 2005 & Postelmans et $\mathrm{al}^{14}$ & $16^{c}$ & $21 \mathrm{mo}$ & PDT & VA improvement in 13 \\
\hline 2006 & Lim et $\mathrm{al}^{15}$ & 2 & I2/24 mo & PDT & $\begin{array}{l}\text { VA improvement in I, } \\
\text { unchanged in I }\end{array}$ \\
\hline 2007 & Coco et $\mathrm{al}^{16}$ & 8 & $22.7 \mathrm{mo}$ & PDT & $\begin{array}{l}\text { VA improvement in } 5 \text {, } \\
\text { deterioration in } 3\end{array}$ \\
\hline 2008 & Fong et $\mathrm{al}^{21}$ & 5 & $12 \mathrm{mo}$ & PDT plus oral steroids & VA improvement in all eyes \\
\hline 2008 & Chan et $\mathrm{al}^{22}$ & 4 & $12 \mathrm{mo}$ & $\begin{array}{l}\text { PDT plus intravitreal } \\
\text { triamcinolone }\end{array}$ & $\begin{array}{l}\text { VA improvement in } 3 \text {, } \\
\text { deterioration in I }\end{array}$ \\
\hline 2008 & Vossmerbaeumer et al $^{17}$ & I & Mid-term & Anti-VEGF (bevacizumab) & VA improvement \\
\hline 2010 & Leung et $\mathrm{al}^{18}$ & I & $8 \mathrm{mo}$ & Anti-VEGF (ranibizumab) & VA improvement \\
\hline
\end{tabular}

Notes: a One case either PIC or multifocal choroiditis. ${ }^{b}$ Mixed results of PIC, POHS, MCP, and other inflammatory conditions. ${ }^{~}$ Mixed cohort of PIC and POHS cases. Juxtafoveal lesion.

Abbreviations: VA, visual acuity; PDT, photodynamic therapy; PIC, punctate inner choroidopathy; POHS, presumed ocular histoplasmosis-like syndrome; MCP, multifocal choroiditis, and panuveitis.

and Leung et $\mathrm{al}^{18}$ reported favorable results in a case with intravitreal ranibizumab after a short-term follow-up.

PDT is generally safe and effective for subfoveal CNV in age-related macular degeneration and high myopia. For other CNV etiologies, PDT is an option if outcome without treatment is likely to be poor, and preliminary success in ocular histoplasmosis syndrome, angioid streaks, idiopathic, and other conditions has been reported. ${ }^{10,11}$ Our results correlate with the ones reported by other authors ${ }^{11-16}$ further substantiating PDT as an effective treatment option in CNV due to PIC. It also adds to relevant literature a small but significant cohort of patients with long-term follow-up, which highlights the prolonged effectiveness of PDT in this patient group. The natural course of the disease is also demonstrated in our study with the presentation of a number of patients left untreated. Some of this group retained a functional visual acuity even after a long follow-up, implying that active neovascularization may recede leaving macula relatively unharmed.

Allowing for obvious limitations, such as the small number of cases and the retrospective review of patient records, our study contributes mainly with the long-term follow-up to the limited body of literature regarding CNV due to PIC.

\section{Disclosure}

The authors report no conflicts of interest in this work.

\section{References}

1. Watzke RC, Packer JA, Folk JC, Benson WE, Burgess D, Ober RP. Punctate inner choroidopathy. Am J Ophthalmol. 1984;98:572-584.

2. Brown J, Folk JC, Reddy CV, Kimura AE. Visual prognosis of multifocal choroiditis, punctate inner choroidopathy, and the diffuse subretinal fibrosis syndrome. Ophthalmology. 1996;103:1100-1115.

3. Akman A, Kadayifcilar S, Aydin P. Indocyanine green angiographic findings in a case of punctate inner choroidopathy. Eur J Ophthalmol. 1998;8:191-194.

4. Levy J, Shneck M, Klemperer I, Lifshitz. Punctate inner choroidopathy: resolution after oral steroid treatment and review of the literature. Can J Ophthalmol. 2005;40:605-608.

5. Gerstenblith AT, Thorne JE, Sobrin L, et al. Punctate inner choroidopathy: a Survey Analysis of 77 Persons. Ophthalmology. 2007;114: 1201-1204.

6. Olsen TW, Capone A, Sternberg P, Grossniklaus HE, Martin DF, Aaberg TM. Subfoveal choroidal neovascularization in punctate inner choroidopathy. Surgical management and pathologic findings. Ophthalmology. 1996;103:2061-2069.

7. Adelberg DA, Del Priore LV, Kaplan HJ. Surgery for subfoveal membranes in myopia, angioid streaks, and other disorders. Retina. 1995;15:198-205.

8. Brueggeman RM, Noffke AS, Jampol L. Resolution of punctate inner choroidopathy lesions with oral prednisone therapy. Arch Ophthalmol. 2002;120:996.

9. Hoerauf H, Laqua H. Punctate inner choroidopathy. Klin Monbl Augenheilkd. 1994;204:535-537. 
10. Rogers A, Duker J, Nichols N, Baker B. Photodynamic therapy of idiopathic and inflammatory choroidal neovascularization in young adults. Ophthalmology. 2003;110:1315-1320.

11. Sickenberg M, Schmidt-Erfuth U, Miller JW, et al. A preliminary study of photodynamic therapy using verteporfin for choroidal neovascularization in pathologic myopia, ocular histoplasmosis syndrome, angioid streaks, and idiopathic causes. Arch Ophthalmol. 2000;117:327-336.

12. Wachtlin J, Heimann H, Behme T, Foerster MH. Long-term results after photodynamic therapy with verteporfin for choroidal neovascularizations secondary to inflammatory chorioretinal diseases. Graefes Arch Clin Exp Ophthalmol. 2003;241:899-906.

13. Chatterjee S, Gibson JM. Photodynamic therapy: a treatment option in choroidal neovascularization secondary to punctate inner choroidopathy. Br J Ophthalmol. 2003;87:917-927.

14. Postelmans L, Pasteels B, Coquelet P, et al. Photodynamic therapy for subfoveal classic choroidal neovascularization related to punctate inner choroidopathy (PIC) or presumed ocular histoplasmosis-like syndrome (POHS-like). Ocul Immunol Inflamm. 2005;13:361-366.

15. Lim J, Flaxel C, LaBree L. Photodynamic therapy for choroidal neovascularization secondary to inflammatory chorioretinal disease. Ann Acad Med Singapore. 2006;35:198-202.

16. Coco RM, de Souza CF, Sanabria MR. Photodynamic therapy for subfoveal and juxtafovela choroidal neovascularization associated with punctate inner choroidopathy. Ocul Immunol Inflamm. 2007;15:27-29.
17. Vossmerbaeumer U, Spandau UH, V Baltz S, Wickenhaeuser A, Jonas JB. Intravitreal bevacizumab for choroidal neovascularization secondary to punctate inner choroidopathy. Clin Experiment Ophthalmol. 2008;36:292-294

18. Leung AK, Weisbrod DJ, Schwartz C. Intravitreal ranibizumab in the treatment of choroidal neovascular membrane secondary to punctate inner choroidopathy. Can J Ophthalmol. 2010;45:1-2.

19. Flaxel CJ, Owens SL, Mulholland B, Schwartz SD, Gregor ZJ. The use of corticosteroids for choroidal neovascularization in young patients. Eye (Lond). 1998;12:266-272.

20. Ishibashi T, Miki K, Sorgente N, Patterson R, Ryan SJ. Effects of intravitreal administration of steroids on experimental subretinal neovascularization in subhuman primate. Arch Ophthalmol. 1985;103:708-711.

21. Fong KC, Thomas D, Amin K, Inzerillo D, Horgan SE. Photodynamic therapy combined with systemic corticosteroids for choroidal neovascularization secondary to punctate inner choroidopathy. Eye (Lond). 2008;22:528-533

22. Chan WM, Lai T, Lau T, Lee V, Liu D, Lam D. Combined photodynamic therapy and intravitreal triamcinolone for choroidal neovascularization secondary to punctate inner choroidopathy or of idiopathic origin: oneyear results of a prospective series. Retina. 2008;28:71-80.
Clinical Ophthalmology

\section{Publish your work in this journal}

Clinical Ophthalmology is an international, peer-reviewed journal covering all subspecialties within ophthalmology. Key topics include: Optometry; Visual science; Pharmacology and drug therapy in eye diseases; Basic Sciences; Primary and Secondary eye care; Patient Safety and Quality of Care Improvements. This journal is indexed on

\section{Dovepress}

PubMed Central and CAS, and is the official journal of The Society of Clinical Ophthalmology (SCO). The manuscript management system is completely online and includes a very quick and fair peer-review system, which is all easy to use. Visit http://www.dovepress.com/ testimonials.php to read real quotes from published authors. 